\title{
Biochemical responses to anoxia and hypoxia in the ark shell Scapharca kagoshimensis
}

\author{
Yasushi Miyamoto \& Chitose Iwanaga \\ Tottori Prefectural Institute of Public Health and Environmental Science, 526-1 Minamidani, Yurihama-cho, Tottori 682- \\ 0704, Japan
}

Received 12 July 2011; Accepted 10 August 2012

\begin{abstract}
Metabolic adaptation to 7-d sustained anoxia, and the activation of anaerobic metabolism by a series of $\mathrm{O}_{2}$ concentrations during a 12-h period, were examined in the ark shell Scapharca kagoshimensis. Laboratory experiments and biochemical analyses were conducted under summer conditions. The pattern of metabolic adaptation to prolonged anoxia was clearly biphasic, similar to that in many other bivalve species. The first, transition stage lasted $12 \mathrm{~h}$ and was characterized by sharp decreases in adenylate energy charge, aspartate consumption, and accumulation of succinate and alanine. The second, stationary stage was characterized by glycogen depletion and propionate accumulation. In a series of dissolved oxygen (DO) conditions, the onset of anaerobic metabolism (as indicated by a decrease in fermentative substrate, aspartate; and increase in the end-products, succinate and alanine) was detected only under hypoxic conditions $\left(<2 \mathrm{mg} \mathrm{O}_{2} \mathrm{~L}^{-1}\right)$ and was accompanied by depressed physiological performance, as measured by clearance rate and ammonium excretion rate. However, under milder hypoxia $\left(1-2 \mathrm{mg} \mathrm{O}_{2} \mathrm{~L}^{-1}\right)$, a significant clearance rate was still observed, suggesting that both aerobic and anaerobic metabolisms were contributing toward the ATP yield. Lower DO $\left(<0.61 \mathrm{mg} \mathrm{O}_{2} \mathrm{~L}^{-1}\right)$ resulted in an increased rate of anaerobic metabolism and inactivated aerobic ATP production due to impaired filter feeding.
\end{abstract}

Keywords: anaerobic metabolism, anoxia, hypoxia, Lake Nakaumi, Scapharca kagoshimensis

\section{Introduction}

Many benthic organisms, including molluscs, polychaetes, oligochaetes, and echinoderms, can survive under hypoxia (even anoxia) by activating anaerobic metabolism over time scales ranging from hours to days (Ellington 1975, de Zwaan et al. 1993, Dubilier et al. 1997, Grieshaber \& Volkel 1998). Anaerobic metabolism is an alternative ATP-yielding pathway in an oxygen-deficient environment when aerobic ATP production proves insufficient to meet energy demand. However, the ATP yield per mole of fermentable substrate (i.e. glycogen) is always modest compared to that in aerobic metabolism (Hochachka \& Somero 2002). Even the energy-efficient anaerobic metabolic pathways resulting in the accumulation of succinate and propionate are well below the efficiency of aerobic metabolism (Seibel 2011). Therefore, activation of anaerobic metabolism pathways requires large stores of fermentable sub-

\footnotetext{
* Corresponding author: Yasushi Miyamoto; E-mail, miyamoto-Y@pref. tottori.jp
}

strates, and depletion of energy reserves during sustained hypoxia or anoxia eventually results in impaired function or death (Connett et al. 1990).

A large body of data is available on anaerobic metabolism in bivalves, involving anaerobic end-product accumulation, anaerobic depletion of fermentable substrate, and depletion of adenylates and phosphagens (e.g. Eertman et al. 1993, de Zwaan et al. 1995, Isani et al. 1995, Sukhotin \& Pörtner 1999). Recently, this knowledge has been applied to stock management and conservation of commercial bivalves (Nakamura 1997, Higano 2005, Matsui et al. 2007, Sugino et al. 2009). In particular, data regarding the concentrations of fermentative substrates and end-products in bivalve tissues, as well as the critical $p \mathrm{O}_{2}$ value at which anaerobic ATP production is activated, have often been recognized as a metabolic status and potential means for survival in an oxygen-deficient environment (de Zwaan et al. 1991, Higano 2005, Moullac et al. 2007). However, less attention has been focused on the anaerobic performance of individual species, in particular, regard to biochemical analyses specific for the ark shell Scapharca kagoshimensis 
(Tokunaga, 1906). Considering that the ark shell is suffering from a growing summer hypoxia and anoxia in coastal waters such as the Ariake Bay (Yoshino et al. 2007, Honda et al. 2010) and the brackish lagoon Lake Nakaumi (Suzuki et al. 2011), this information would be valuable.

The aims of this study are to characterize the biochemical response to anoxia, and to detect the DO threshold below which anaerobic metabolism is activated in $S$. kagoshimensis. The initial experiment was carried out to characterize the biochemical changes activated in $S$. kagoshimesis under summer anoxia, particularly changes in high-energy phosphate reserves (adenylate energy charge), and in the substrates (aspartate and glycogen) and products of anaerobic metabolism (alanine, succinate, and propionate). The second experiment was designed to detect the critical $\mathrm{O}_{2}$ level at which anaerobic metabolism is activated by assessing changes in anaerobic metabolites. The critical dissolved oxygen (DO) level for ammonium excretion rate, as an indicator of physiological performance, was also evaluated. A third experiment was performed to detect the DO threshold below which clearance rate is inhibited: another indicator of physiological performance. The features of metabolic adaptation to anoxia and critical $p \mathrm{O}_{2}$ for the ark shell are briefly compared with those of other bivalve species.

\section{Materials and Methods}

\section{Animals}

The ark shell, S. kagoshimensis, is a suspension-feeding bivalve that normally inhabits relatively muddy sediments, and was formerly a major fisheries target in the brackish lagoon Lake Nakaumi $\left(35^{\circ} 27^{\prime} 59^{\prime \prime} \mathrm{N}, 133^{\circ} 11^{\prime} 29^{\prime \prime} \mathrm{E}\right)$. However, this species was almost extirpated during the 20th century, probably because of expanding hypoxia (Suda et al. 1929, Shimane Pref. 1934, 1958), therefore cultured individuals were used for the series of experiments in this study. The ark shell was cultured in pearl nets hung at a depth of $1.0-1.5 \mathrm{~m}$ in Lake Nakaumi (temperature 4.9$28.4^{\circ} \mathrm{C}$, salinity $17.3-24.6$ ) (Uye et al. 2000) for a period of approximately 1.5 year after larval settlement. Mean shell length of the clams used in the study was $28.2 \pm 1.71 \mathrm{~mm}$ (SD).

After collection in May 2010, individuals were immediately transported to the laboratory, placed in an aquarium with well-aerated seawater $(60 \mathrm{~L})$ and sandy sediment, and acclimated to experimental conditions (temperature $28^{\circ} \mathrm{C}$, salinity 30) over a period of 7 days. The seawater was transported from the shore nearby the laboratory. During the acclimation period, media DO was maintained at $100 \%$ by bubbling with air-stones, and the animals were fed the diatom Chaetoceros ceratosporus Ostenfeld, 1910. Daily, $c a .40 \%$ of the water was replaced to prevent ammonia build-up.

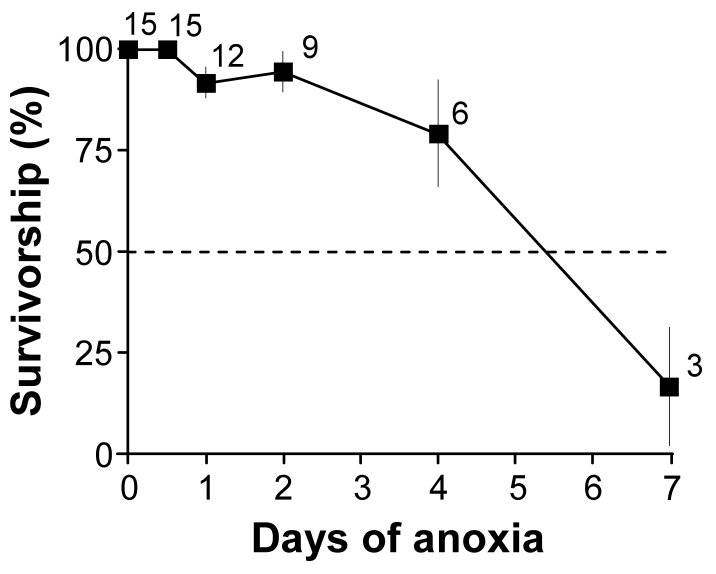

Fig. 1. Survival profiles of Scapharca kagoshimensis individuals subjected to incubation in anoxic sea water at $28^{\circ} \mathrm{C}$. A number above each symbol indicates the number of replicated incubation bottles at each assessment. Data are means \pm 1 SE.

\section{Experiment 1: Effect of anoxia on metabolic pathways}

The pattern of metabolic adaptation to anoxia was tested following exposure to different anoxic conditions, with measurements of aspartate and glycogen as the metabolic substrates; alanine, succinate and propionate as the products; and the nucleotides ATP, ADP, and AMP as the energy reserves. Four specimens of $S$. kagoshimensis were placed in each of 5 incubation bottles each containing $1.0 \mathrm{~L}$ of filtered seawater (salinity 30 ) previously flushed with nitrogen gas. This water was held at $28^{\circ} \mathrm{C}$, and not replaced during the experiment. No food was added during the experiment. After $0.5,1,2,4$, and $7 \mathrm{~d}$, animals were sampled from a randomly chosen bottle, and rapidly dissected by excising the posterior adductor muscle (referred to hereafter as the adductor muscle). Three live individuals were pooled as 1 sample for each treatment period, except at 7-d, when most of the individuals were dead (Fig. 1). Mortality was assessed by constriction failure after the mantle edge of gaping animals was touched before each sampling. The adductor muscle samples were stored and frozen at $-40^{\circ} \mathrm{C}$ until used. Control $(0 \mathrm{~d})$ animals in the pre-culture aquaria were similarly sampled, dissected, and frozen. The experiment was replicated 3 times.

\section{Experiment 2: Effect of oxygen levels on metabolites and ammonium excretion rate}

In this experiment, the critical DO level at which anaerobic metabolism was activated and ammonium excretion rate (an indicator of physiological performance) was inhibited were tested during 12-h exposure under various DO conditions. Only the metabolites succinate, alanine, and aspartate were measured in the earlier stage of anaerobiosis, since the duration of the experiment $(12 \mathrm{~h})$ was probably insufficient to activate the later anaerobic phase for the ark shell (Honda et al. 2010). Four individuals were placed 
Table 1. Laboratory measurement of ammonium excretion rate by Scapharca kagoshimensis with various oxygen levels. Excretion rates were calculated from regression slopes of the ammonium concentration per animal weight in the experimental media with respect to time.

\begin{tabular}{|c|c|c|c|}
\hline $\begin{array}{l}\text { Target DO } \\
\left(\mathrm{mg} \mathrm{O}_{2} \mathrm{~L}^{-1}\right)\end{array}$ & $\begin{array}{l}\text { Bivalve } \\
\text { weight } \\
\text { (wet g) }\end{array}$ & $\begin{array}{c}\text { Excretion rate } \\
\left(\mathrm{mmol} \text { wet } \mathrm{g}^{-1} \mathrm{~h}^{-1}\right)\end{array}$ & $r^{2}$ \\
\hline 0 & 12.3 & -0.001 & 0.002 \\
\hline 0.5 & 14.6 & 0.034 & 0.948 \\
\hline 1.0 & 12.6 & 0.110 & 0.996 \\
\hline 1.5 & 10.6 & 0.116 & 0.990 \\
\hline 2.0 & 12.2 & 0.203 & 0.992 \\
\hline 3.0 & 12.5 & 0.169 & 0.989 \\
\hline Saturated & 12.1 & 0.215 & 0.991 \\
\hline
\end{tabular}

in each of 7 incubation bottles each containing $2.0 \mathrm{~L}$ filtered seawater (salinity 30 , temperature $28^{\circ} \mathrm{C}$ ). The six lower DO values $\left(0,0.5,1.0,1.5,2.0\right.$, and $\left.3.0 \mathrm{mg} \mathrm{O}_{2} \mathrm{~L}^{-1}\right)$ and hyper-saturated $\left(c a .7 .6 \mathrm{mg} \mathrm{O}_{2} \mathrm{~L}^{-1}\right)$ conditions were attained by continuous bubbling with appropriate mixtures of $\mathrm{N}_{2}$ and $\mathrm{O}_{2}$ gases from pre-mixed gas cylinders. Generally, it took $c a$. $1 \mathrm{~h}$ to reach the required oxygen concentrations. After $1.5 \mathrm{~h}$ the bubbling was initiated, animals were introduced into incubation bottles. No food was added during the experiments.

The rate of ammonium excretion at each oxygen level was estimated in the experiment according to Mokady et al. (1998). A $20 \mathrm{~mL}$ water sample was withdrawn from each bottle by using a syringe at $0,2,3,7.5$, and $12 \mathrm{~h}$ after introducing the animals into bottles. Analysis of the samples for ammonium concentrations was performed according to the protocol published by the Japan Fisheries Resource Conservation Association (1980). Excretion rates were calculated from regression slopes of the ammonium concentration per gram animal weight with respect to time. The regressions fitted well linearly $\left(r^{2}>0.94\right)$, except for the $0 \mathrm{mg} \mathrm{O}_{2} \mathrm{~L}^{-1}$ treatment (Table 1).

After a 12-h exposure at each DO level, all animals were rapidly dissected by excising whole soft tissue samples on ice, weighed, rapidly frozen in liquid nitrogen, and stored at $-40^{\circ} \mathrm{C}$. Analysis of whole body concentrations of anaerobic metabolites enables comparison with a previous study that detected the DO threshold below which anaerobic metabolism is activated in Andara (originally as Scapharca) inaequivalvis (Bruguiere 1789) and Mytilus galloprovincialis Lamarck, 1819, as reported by de Zwaan et al. (1991).

\section{Experiment 3: Effect of oxygen levels on clearance rate}

The clearance rate (removal of suspended food organisms by the mechanism of filter feeding) is another indicator of physiological performance. This was estimated at each DO level by a separate experiment under conditions identical to those described above. Feeding and water sam- pling were repeated at $3,6,9$, and $12 \mathrm{~h}$ after initiation of the experiment; each $20 \mathrm{~mL}$ sample removed $5 \mathrm{~min}$ after feeding the ark shells with $C$. ceratosporus, (5 min allowing for thorough mixing of the algal cells). Further (tandem) samples were collected from each bottle 20 min after the first sampling and remaining free $C$. ceratosporus was measured. Fluorescence levels were recorded immediately after each sampling using a chlorophyll sensor (CHL-30; Kasahara Rikakogyo, Ltd.). Following the experiment, soft tissue was removed from all the shells in each bottle, dried, and weighed.

Clearance rate (CR) is defined as the volume of water cleared of suspended particles per unit time per unit weight of ark shell, calculated using the formula:

$$
\mathrm{CR}=\left[V / t \times \ln \left(\mathrm{C}_{20}-\mathrm{C}_{0}\right)-\mathrm{CR}^{*}\right] / w
$$

where CR is clearance rate $\left(\mathrm{L} \mathrm{h}^{-1} \mathrm{~g}^{-1}\right), V$ is volume of water used (L), $t$ is time increment (h), $\mathrm{C}_{0}$ and $\mathrm{C}_{20}$ are fluorescence levels between the 2 tandem sampling times, $\mathrm{CR}^{*}$ is the apparent clearance rate in control bottles $\left(\mathrm{L} \mathrm{h}^{-1}\right)$, and $w$ is $S$. kagoshimensis dry tissue weight.

\section{Extraction and analysis of metabolites}

Frozen samples were homogenized $\left(1 \mathrm{~g} \mathrm{~mL}^{-1}\right)$ in icecold 5\% trichloro-acetic acid (TCA) using a Polytron homogenizer (PT10-35; Polytron, Ltd.). The homogenate was centrifuged $(10 \mathrm{~min}, 10,000 \times g)$ at $4^{\circ} \mathrm{C}$. The resulting pellet was re-homogenized in 4 volumes of 5\% TCA and centrifuged again. The first and second supernatants were then combined and neutralized with $\mathrm{KOH}$ for metabolite analysis. Organic acids and free amino acids accumulated in the tissues of S. kagoshimensis were determined by HPLC according to the methods of Nakamura (1997) and Shimadzu (2005), respectively. Adenylate analyses were carried out by HPLC with a TSK gel (ODS-100S $250 \times 4.6 \mathrm{~mm}$ column; TOSOH), using a continuous gradient eluent at a flow rate of $0.6 \mathrm{~mL} \mathrm{~min}^{-1}$. The elution program was as follows:

0-min: $100 \%$ mobile phase A

2-min: $95 \%$ mobile phase A and 5\% mobile phase B

4-min: $80 \%$ mobile phase A and $20 \%$ mobile phase B

6-min: $75 \%$ mobile phase A and $25 \%$ mobile phase B

12-min: 50\% mobile phase A and 50\% mobile phase B where mobile phase A consisted of $0.1 \mathrm{~mol} \mathrm{~L}^{-1}$ potassium phosphate buffer ( $\mathrm{pH}$ 7.2), and mobile phase B was $100 \%$ acetonitrile. The peaks were detected and analyzed at 258 $\mathrm{nm}$ using a photodiode array detector. The injection volume was $10 \mu \mathrm{L}$, and the column temperature was maintained at $40^{\circ} \mathrm{C}$. Each HPLC analysis was performed on a Shimadzu LC10.

Adenylate energy charge (AEC) was established according to the method of Atkinson (1968) by using the formula: $\mathrm{AEC}=[(\mathrm{ATP}+1 / 2 \mathrm{ADP}) /(\mathrm{ATP}+\mathrm{ADP}+\mathrm{AMP})]$. Glycogen was quantified as glucose by the anthrone-sulphuric acid method (Carroll et al. 1955) after precipitation of glycogen 
with $100 \%$ ethanol. Standard organic acids (succinate and propionate), amino acids (L-alanine and L-aspartate), nucleotides (ATP, ADP, and AMP), and glucose were purchased from Wako Pure Chemical Industries, Ltd.

\section{Statistics}

Confidence intervals $(95 \%)$ were estimated for replicated data (metabolites and clearance rate) by 2,000 bootstraping processes using $\mathrm{R}$ ver. 2.12.2. The parametric bootstrap was used, since the physiological and biochemical responses to hypoxia and anoxia by bivalves are deterministic mechanisms (e.g. de Zwaan et al. 1991, Isani et al. 1995); thus, a normal frequency distribution was expected for each parameter.
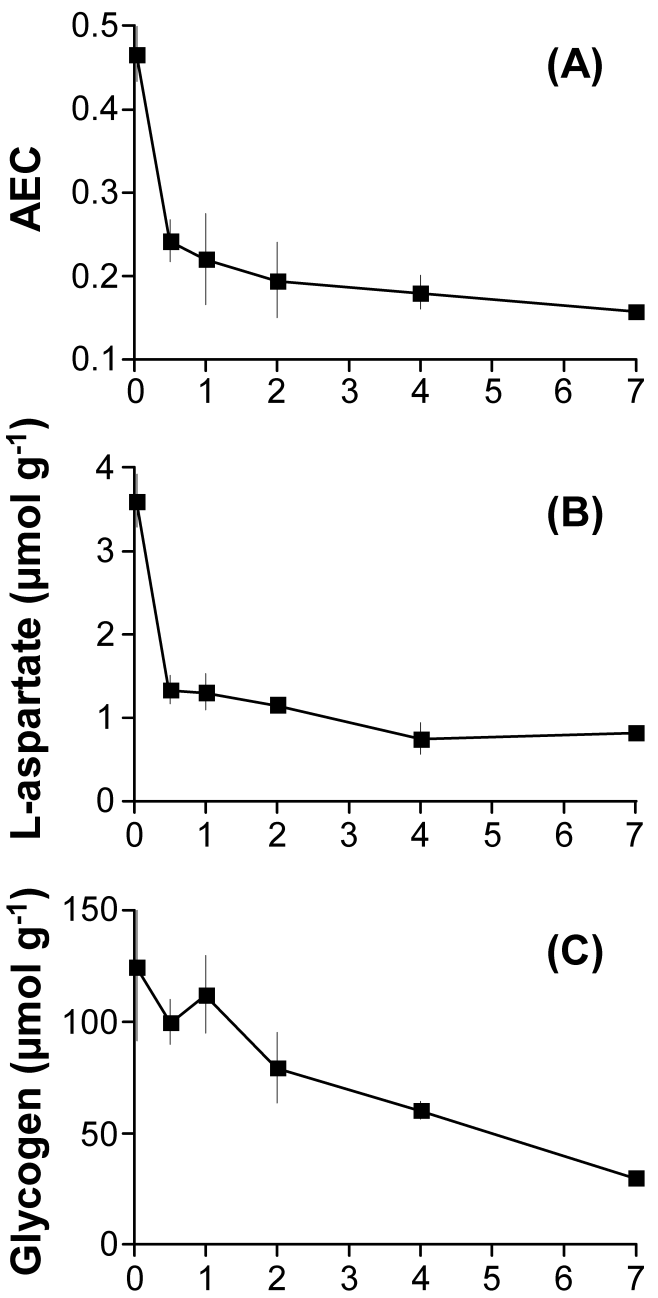

\section{Results}

\section{Experiment 1: Effect of anoxia on metabolic pathways}

Survival of Scapharca kagoshimensis was $>90 \%$ for up to $2 \mathrm{~d}$ of anoxia, but began to decline at $4 \mathrm{~d}$ (Fig. 1) and at final sampling $(7 \mathrm{~d})$ was $16.7 \%$. The $\mathrm{Lt}_{50}$ in anoxia was $5.3 \mathrm{~d}$ (Fig. 1). During the first $12 \mathrm{~h}$, there was a rapid decrease in AEC, followed by a more gradual decrease for up to $7 \mathrm{~d}$ (Fig. 2A). The levels of aspartate and glycogen, the substrates of anaerobic metabolism, also decreased during the 7-d anoxic period (Fig. 2B, C). The temporal trend in aspartate level was identical to AEC: an initial sharp decrease during the first $12 \mathrm{~h}$ followed by a slow decrease (Fig. 2B). In contrast, this pattern was not evident for glycogen: no significant changes were detected after $1 \mathrm{~d}$ but there was a gradual decrease as the anoxic period pro-
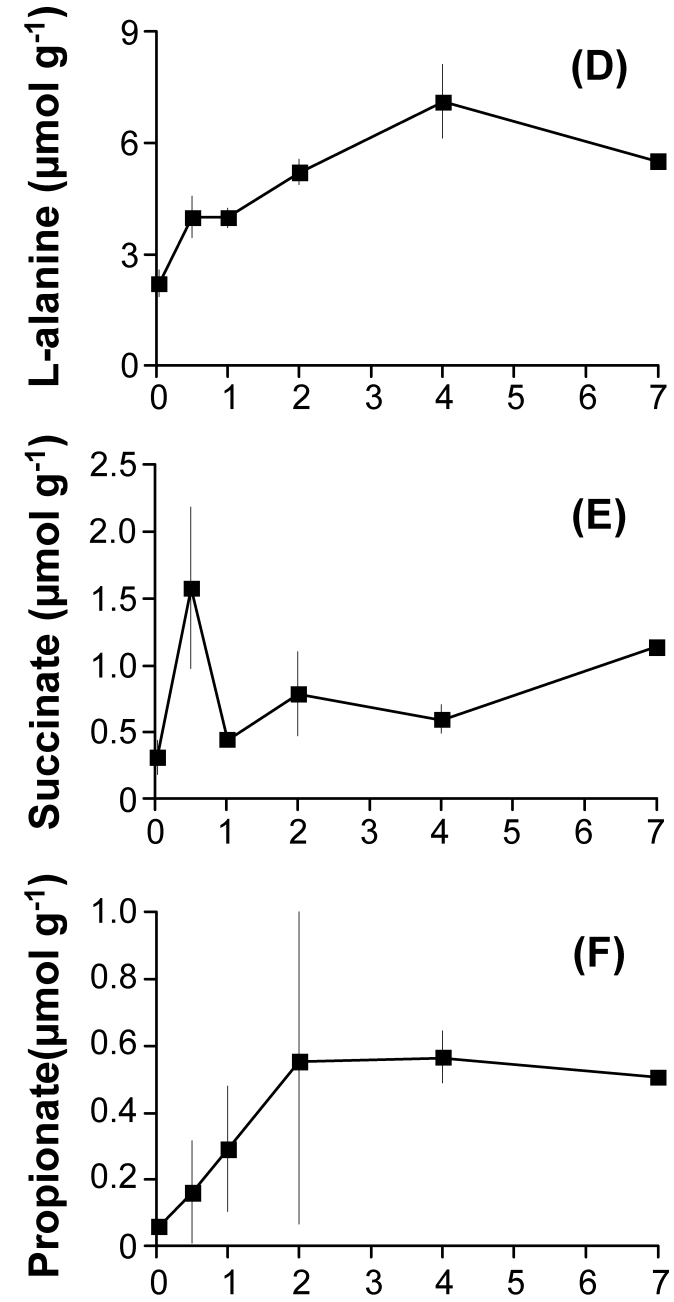

\section{Days of anoxia}

Fig. 2. Adenylate energy charge (AEC) (A), concentrations of L-aspartate (B), glycogen (C), L-alanine (D), succinate (E) and propionate (F) in adductor muscle of Scapharca kagoshimensis at each sampling (days 0, 0.5, 1, 2, 4, and 7 after initiation) subjected to incubation in anoxic sea water $(30 \mathrm{psu})$ at $28^{\circ} \mathrm{C}$. Data are means $\pm 95 \% \mathrm{CI}$. 

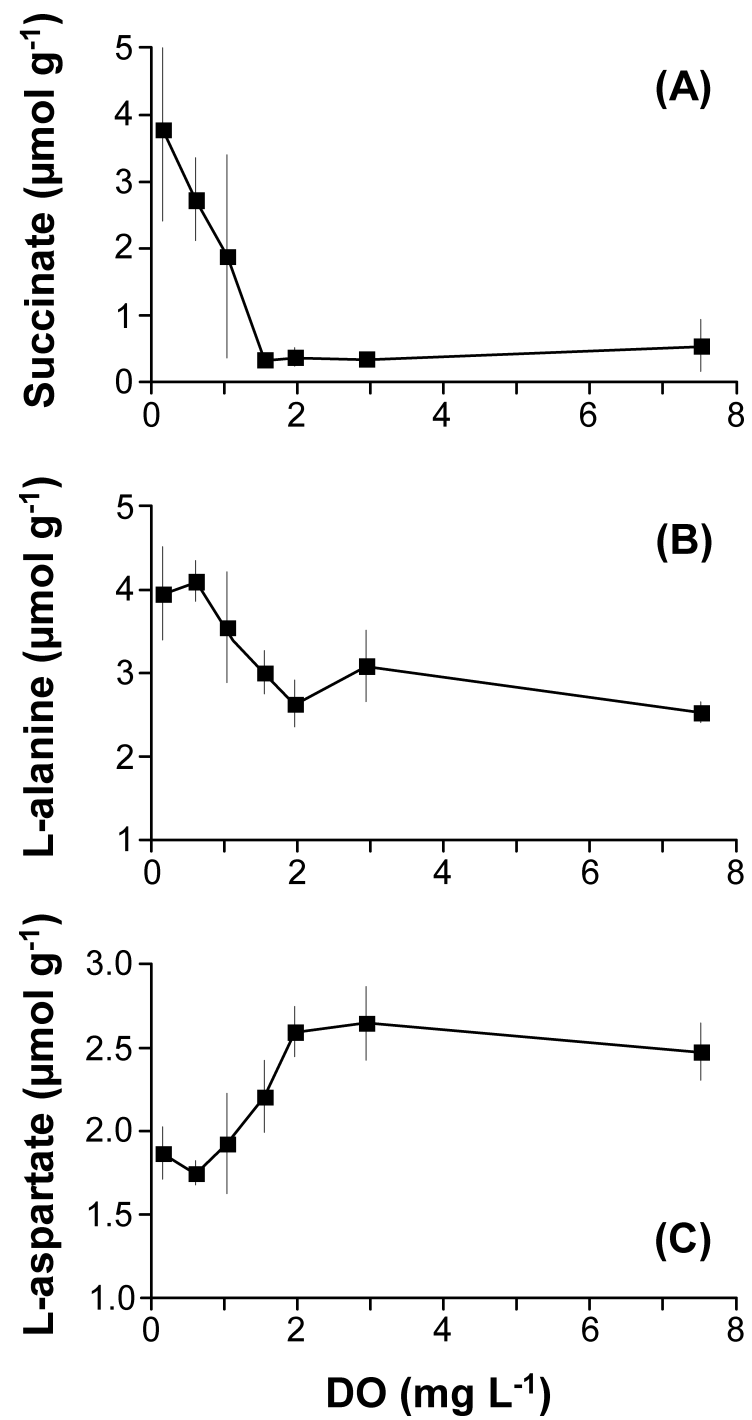

Fig. 3. Concentrations of succinate (A), L-alanine (B), and Laspartate (C) in whole body of Scapharca kagoshimensis after 12-h exposure to different oxygen levels. Salinity and temperature were 30 and $28^{\circ} \mathrm{C}$, respectively. Data are means $\pm 95 \% \mathrm{CI}$.

gressed and the content in survivors after $7 \mathrm{~d}$ was about $20 \%$ of that in the control animals (Fig. 2C).

The end products of anaerobic metabolism accumulated during the 7-d anoxic period but with no clear pattern (Fig. 2D-F). Alanine increased up to $4 \mathrm{~d}$ and then declined (Fig. 2D), whereas succinate accumulation reached its maximum after $12 \mathrm{~h}$ and then fluctuated between 0.5 and $1.0 \mu \mathrm{mol} \mathrm{g}^{-1}$ (Fig. 2E). Propionate rose steadily over the first $2 \mathrm{~d}$ and then remained at around $0.5 \mu \mathrm{mol} \mathrm{g}^{-1}$ (Fig. 2F).

\section{Experiment 2: Effect of oxygen levels on metabolites and ammonium excretion rate}

Below $1.96 \mathrm{mg} \mathrm{O}_{2} \mathrm{~L}^{-1}$, the end products of anaerobic metabolism (i.e. succinate and alanine) showed a progressive inverse relationship with oxygen concentration and
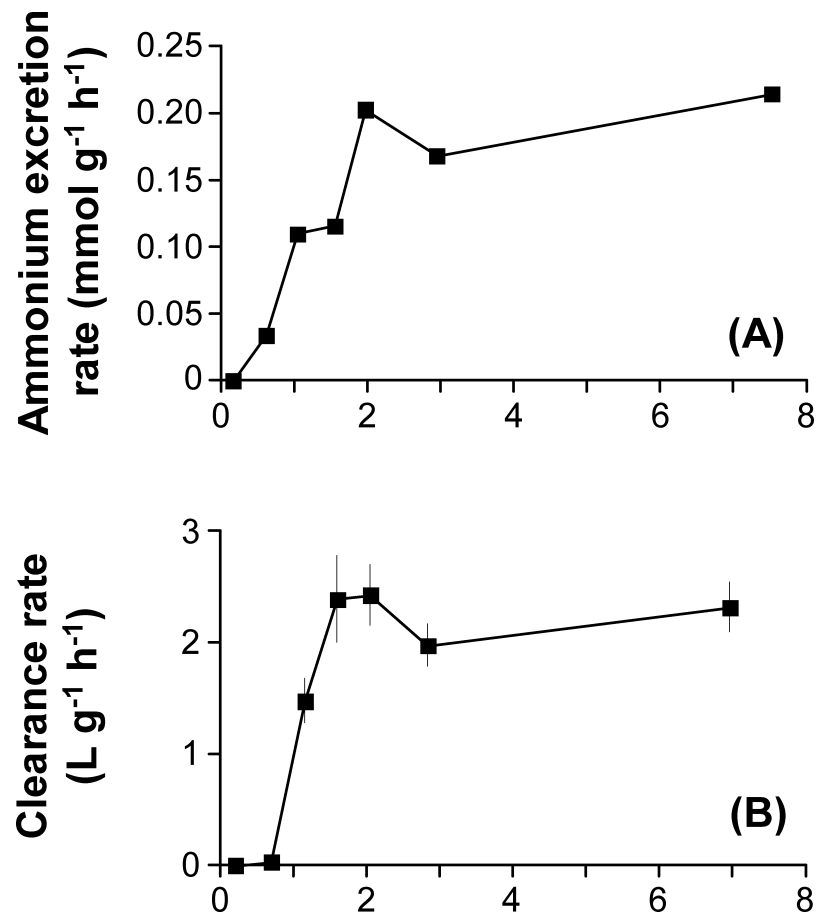

Fig. 4. Ammonium excretion rate (A) and clearance rate (B) by Scapharca kagoshimensis individuals during 12-h exposure to different oxygen levels. Salinity and temperature were 30 and $28^{\circ} \mathrm{C}$, respectively. Data in Fig. $4 \mathrm{~B}$ are means $\pm 95 \%$ CI.

substrate (aspartate) showed a direct decrease (Figs. 3AC). Levels of succinate and alanine significantly higher than the control treatment (saturated DO) were first detected for animals exposed to 0.61 and $1.55 \mathrm{mg} \mathrm{O}_{2} \mathrm{~L}^{-1}$ respectively (Figs. 3A, B). The first significantly lower aspartate content was detected with ark shells incubated at $1.55 \mathrm{mg} \mathrm{O}_{2} \mathrm{~L}^{-1}$ (Fig. 3C).

A lowered ammonium excretion rate became obvious at a DO level of $1.55 \mathrm{mg} \mathrm{O}_{2} \mathrm{~L}^{-1}$ and no detectable excretion was observed at $0.16 \mathrm{mg} \mathrm{O}_{2} \mathrm{~L}^{-1}$ (Fig. 4A). This decline was correlated inversely with anaerobic metabolite concentration (Figs. 3A, B): correlation coefficients $r=-0.906$ ( $v s$. succinate) and -0.953 (vs. alanine); and there was a direct correlation of $r=0.893$ between ammonium excretion and aspartate (all coefficients were significant at $p<0.01$ ).

\section{Experiment 3: Effect of oxygen levels on clearance rate}

The clearance rate remained unchanged against control DO as low as $1.55 \mathrm{mg} \mathrm{O}_{2} \mathrm{~L}^{-1}$, with the first significant decrease detected at $1.04 \mathrm{mg} \mathrm{O}_{2} \mathrm{~L}^{-1}$ and was not detected below $0.61 \mathrm{mg} \mathrm{O}_{2} \mathrm{~L}^{-1}$ (Fig. 4B). As observed for the ammonium excretion rate, clearance rate correlated inversely with the anaerobic end-products succinate $(r=-0.958)$ and alanine $(r=-0.945)$, and directly with the substrate aspartate $(r=0.829)$ : all coefficients were significant $(p<0.01)$. 


\section{Discussion}

\section{Anaerobic metabolism of Scapharca kagoshimensis}

The biphasic pattern of metabolic adaptation to anoxia has been reported for various bivalve species (de Zwaan et al. 1993, 1995, Isani et al. 1995, Ortmann \& Grieshaber 2003). The first stage (transition stage) was summarized as (1) a sharp drop in adenylate energy charge (AEC), (2) consumption of aspartate accompanied by the accumulation of succinate and alanine, and (3) an ATP turnover rate higher than that during prolonged anoxia. The second stage (stationary stage) was characterized by (1) depletion of glycogen stores, (2) production of propionate, and (3) a lower ATP turnover rate. An identical trend was recognized for Scapharca kagoshimensis in the present study: the steep decrease in AEC, consumption of aspartate, and accumulation of alanine and succinate in the first stage lasted for $12 \mathrm{~h}$ (Fig. 2A, B, D, E); followed by glycogen depletion and propionate production in the second stage (Fig. 2C, F). These results indicate that biphasic metabolic adaptation to sustained anoxia is also a feature of $S$. kagoshimensis.

The transition stage of anaerobiosis in S. kagoshimensis seems to be similar to that found in other bivalve species. For example, a rapid decrease in aspartate and increase in succinate after the initiation of anoxia (Fig. 2B, E) has also been reported for Andara (originally as Scapharca) inaequivalvis (de Zwaan et al. 1995), Andara (originally as Scapharca) broughtonii (Watanabe et al. 2005), M. galloprovincialis (Isani et al. 1995), and the fresh water cyrenids Corbicula fluminea (Ortmann \& Grieshaber 2003), and C. japonica (Nakamura 1997). During this period of initial anoxia, the aspartate-succinate pathway is activated to produce ATP (de Zwaan et al. 1995); therefore, aspartate was consumed and succinate accumulated rapidly in the tissues (Fig. 2B, E). The rapid decrease in AEC due to ATP consumption and the consequent accumulation of AMP is also a feature of the transition stage (de Zwaan et al. 1995, Isani et al. 1995); as found also for S. kagoshimensis (Fig. 2A).

Propionate accumulation and glycogen depletion after an initial lag period (Fig. 2C, F) has also been reported for various bivalve species (as mentioned above). The delayed accumulation of propionate is due to further conversion of succinate into propionate for additional ATP yields (Hochachka \& Mommsen 1983); this also explains why succinate accumulated at high levels only during the earlier transition stage (Fig. 2B). Another study on S. kagoshimensis also reported delayed propionate accumulation (Honda et al. 2010), which further strengthens the present findings. The initial absence of a decrease in glycogen during long-term anoxia (Fig. 2C) seems to be a general characteristic of bivalves, especially those that contain high levels of glycogen (Hummel et al. 1989, Isani et al. 1989).

\section{Critical $\mathrm{O}_{2}$ level in Scapharca kagoshimensis}

Elevated whole body contents of succinate and alanine, indicative of the recruitment of fermentative pathways for ATP production, became obvious between 1.04 and $1.55 \mathrm{mg} \mathrm{O}_{2} \mathrm{~L}^{-1}$ (Fig. 3A, B), whereas decreased levels of aspartate, the substrate of anaerobic metabolism, occurred between 1.55 and $1.96 \mathrm{mg} \mathrm{O}_{2} \mathrm{~L}^{-1}$ for $S$. kagoshimensis (Fig. 3C). These results indicate that anaerobic metabolism becomes activated near the transition between 1.0 and $2.0 \mathrm{mg} \mathrm{O}_{2} \mathrm{~L}^{-1}$ for this species. However, aerobic ATP production seems to continue, at least at $\mathrm{O}_{2}$ concentrations as low as $1.04 \mathrm{mg} \mathrm{O}_{2} \mathrm{~L}^{-1}$, at which a significant clearance rate was detected (Fig. 4B). This suggests that both aerobic and anaerobic metabolism contribute to the ATP yield with milder hypoxia, between 1.0 and $2.0 \mathrm{mg} \mathrm{O}_{2} \mathrm{~L}^{-1}$, and that both may function simultaneously and not on an "on/off" basis (Livingstone \& Bayne 1977).

Further decreased $\mathrm{O}_{2}$ concentrations $\left(<0.61 \mathrm{mg} \mathrm{O}_{2} \mathrm{~L}^{-1}\right)$ resulted in increased accumulation of anaerobic end-product (succinate) in the bivalve tissues (Fig. 3A). This implies an increased rate of anaerobic ATP production with more severe hypoxia. Within the same oxygen range, however, no significant clearance rates were detected (Fig 4B), suggesting that there was no further aerobic metabolism yielding ATP. This situation may be critical for the ark shell for at least 2 reasons. First, energetically inefficient anaerobiosis requires substantial glycogen stores (Seibel 2011), but additional glycogen is unavailable because filter feeding is inactivated with more severe hypoxia (Fig. 4B). Consequently, glycogen reserves are depleted during anaerobic metabolism as shown in Fig 2C. Second, anaerobic metabolism results in the accumulation of protons as well as various metabolic end products (Hochachka \& Mommsen 1983). Gradual acidification is a well-known consequence of sustained anoxia, and therefore, end-product accumulation has often been linked to acidosis (Hochachka \& Mommsen 1983). A trend for decreasing $\mathrm{pH}$ during sustained anoxia was also observed in the first experiment (from 8.2 to 6.9 within $7 \mathrm{~d}$ ).

Physiological performance (as measured by clearance and ammonium excretion rates) was inhibited at lower $\mathrm{O}_{2}$ concentrations, correlating well with anaerobic metabolite dynamics (absolute values of correlation coefficients between each measure of performance and metabolites ranged from 0.829 to 0.958 ), suggesting some causality between the activation of anaerobic metabolism and inhibited physiological performance. For bivalve cells to survive under hypoxia or anoxia, they must maintain their energy requirement by effectively coupling energy supply and demand (Moullac et al. 2007). Considering a lowered ATP supply in anaerobic metabolism (de Zwaan et al. 1995, Isani et al. 1995), the down-regulated consumption of ATP energy stores under hypoxia and anoxia is reasonable, and physiological performance, including filtering and excretion, might be involved in such regulation. A decreased clearance rate under hypoxic and anoxic conditions has 
also been reported in some previous studies involving bivalves (Nakamura 1997, Sobral \& Widdows 1997, Hicks \& McMahon 2002, Moullac et al. 2007), suggesting that this reasoning is plausible.

\section{Conclusion}

The present study illustrates that hypoxic water $\left(<2 \mathrm{mg} \mathrm{O}_{2} \mathrm{~L}^{-1}\right)$ activates anaerobic metabolism in $\mathrm{S}$. $\mathrm{ka}$ goshimensis to compensate for depressed aerobic ATP production. Furthermore, the anaerobiosis has been proven to shift towards the energy-efficient pathway (consuming glycogen and accumulating propionate) during a prolonged oxygen-deficient period. However, the onset of hypoxia is followed not only by anaerobiosis in S. kagoshimensis but also by a number of changes in the benthic ecosystem, in particular a shift in microbial communities to sulfate reduction and increased sulfide concentrations in the environment (Conley et al. 2009). Consequently, the macrofauna, including bivalves, is exposed to sulfide in the hypoxic environment. Therefore benthic mass mortalities during hypoxia may be a consequence of both sulfide toxicity and oxygen deficiency rather than oxygen deficiency alone (Vistisen \& Vismann 1997, Higano 2005, VaquerSunyer \& Duarte 2010). For further understanding of mass mortality events during the hypoxic period and conservation of the ark shell, the effect of the presence of sulfide on survival under hypoxia requires evaluation.

\section{Acknowledgments}

We thank H. Semura, T. Sasaki and H. Hirakiuchi at the Inland Water Fisheries and Coastal Fisheries Division in Shimane Prefecture for providing ark shells, A. Kato at the Tottori Institute of Industrial Technology for the organic and amino acid analyses, and Dr. A Shinagawa at Gakusyuin Woman's College for his advice on biochemical analyses. Two anonymous reviewers provided valuable comments on the manuscript. This work was supported by research project funds from the Agriculture, Forestry and Fisheries Research Council (Operation to Develop Practical Technology to Promote New Agriculture, Forestry, and Fisheries Technology \# 21007).

\section{References}

Atkinson DE (1968) The energy charge of the adenylate pool as a regulatory parameter. Interaction with feedback modifiers. Biochemistry 7: 4030-4034.

Carroll NV, Longley RW, Roe JJ (1955) The determination of glycogen in liver and muscle by use of anthrone reagent. J Bio Chem 220: 583-593.

Connett RJ, Honig CR, Gayeski TE, Brooks GA (1990) Definig hypoxia: a systems view of $\mathrm{Vo}_{2}$, glycolysis, energetics, and intracellular $\mathrm{Po}_{2}$. J Appl Physiol 68: 833-833.

Conley DJ, Carstensen J, Vaquer-Sunyer R Duarte CM (2009)
Ecosystems thresholds with hypoxia. Hydrobiologia 629: 2129.

de Zwaan A, Cortesi P, van den Thillart G., Roos J, Storey KB (1991) Differential sensitivities to hypoxia by two anoxiatolerant marine molluscs: a biochemical analysis. Mar Biol 111: 343-351.

de Zwaan A, Isani G, Cortesi P, Cattani O, Putzer VM (1993) Conversion of phosphoenolpyruvate in Venus gallina and Scapharca inaequivalvis at anoxia stress-I. Time dependency. Comp Biochem Physiol B 105: 735-741.

de Zwaan A, Isani G., Cattani O, Cortesi P (1995) Long-term anaerobic metabolism of erythrocytes of the arcid clam Scapharca inaequivalvis. J Exp Mar Biol Ecol 187: 27-37.

Dubilier N, Windoffer R, Grieshaber MK, Giere O (1997) Ultrastructure and anaerobic metabolism of mitochondria in the marine oligochaete Tubificoides benedii: Effects of hypoxia and sulfide. Mar Biol 127: 637-645.

Eertman RHM, Wagenvoort AJ, Hummel H, Smaal AC (1993) "Survival in air" of the blue mussel Mytilus edulis L. as a sensitive response to pollution-induced environmental stress. J Exp Mar Biol Ecol 170: 179-195.

Ellington WR (1975) Holothurian facultative anaerobiosis. Am Zool 15: 808-808.

Grieshaber MK, Volkel S (1998) Animal adaptations for tolerance and exploitation of poisonous sulfide. Ann Rev Physiol 60: $33-53$.

Hicks DW, McMahon RF (2002) Respiratory responses to temperature and hypoxia in the nonindigenous Brown Mussel, Perna perna (Bivalvia: Mytilidae), from the Gulf of Mexico. J Exp Mar Biol Ecol 277: 61-78.

Higano J (2005) Influence of environmental factors as oxygen deficiency, hydrogen sulfide and suspended mud on the survival and growth of Manila clam. Bulletin of Fisheries Research Agency 3: 27-33. (in Japanese with English abstract)

Hochachka PW, Mommsen TP (1983) Protons and anaerobiosis. Science 219: 1391-1397.

Hochachka PW, Somero GN (2002) Biochemical adaptation: Mechanism and Process in Physical Evolution. Oxford University Press, Oxford.

Honda M, Gunjikake H, Matsui S, Moroishi J, Kang IJ, Shimasaki Y, Oshima Y (2010) The effect of hypoxia on respiratory metabolism of ark shell (Scapharca kagoshimensis). Sci Bull Fac Agr Kyushu Univ 65: 31-37. (in Japanese with English abstract)

Hummel H, de Wolf L, Zurburg W, Apon L, Bogaards RH, van Ruitenburg M (1989) The glycogen content in stressed marine bivalves: the initial absence of a decrease. Comp Biochem Physiol B 4: 729-733.

Isani G, Cattani O, Carpené E, Tacconi S, Cortesi P (1989) Energy metabolism during anaerobiosis and recovery in the posterior adductor muscle of the bivalve Scapharca inaequivalvis (Bruguirre). Comp Biochem Physiol B 93: 193-200.

Isani G, Cattani O, Zurzolo M, Pagnucco C, Cortesi P (1995) Energy metabolism of the mussel, Mytilus galloprovincialis, during long-term anoxia. Comp Biochem Physiol B 110: 103-113.

Japan Fisheries Resource Conservation Association (1980) Guidelines for water pollution research. Koseisha-koseikaku, Japan. (in Japanese) 
Livingstone DR, Bayne BL (1977) Responses of Mytilus edulis to low oxygen tension. Anaerobic metabolism of posterior adductor muscle and mantle tissues. J Comp Physiol 114: 143-155.

Matsui S, Tanoue W, Watanabe D, Ito T, Yoshida M (2007) The respiratory metabolism of Tairagi from Ariake Sea in the poverty oxygen condition. Bulletin of Fukuoka Fisheries and Marine Technology Research Center 17: 61-66. (in Japanese)

Mokady O, Loya Y, Lazar B (1998) Ammonium contribution from boring bivalves to their coral host-a mutualistic symbiosis-Mar Ecol Prog Ser 169: 295-301.

Moullac GL, Quéau I, Souchu PL, Pouvreau S, Moal J, Coz JRL, Samain JF (2007) Metabolic adjustments in the oyster Crassostrea gigas according to oxygen level and temperature. Mar Biol Res 3: 357-366.

Nakamura M (1997) Physiological and ecological studies on interactive relationship between the brackish water clam Corbicula japonica Prime and environment. Dissertation, Hokkaido University. (in Japanese)

Ortmann C, Grieshaber MK (2003) Energy metabolism and valve closure behaviour in the Asian clam Corbicula fluminea. J Exp Biol 206: 4167-4178.

Seibel BA (2011) Critical oxygen levels and metabolic suppression in oceanic oxygen minimum zones. J Exp Biol 214: $326-$ 336.

Shimadzu (2005) Analysis of amino acids in vinegar. Shimadzu application news No. L323.

Shimane Prefecture (1934) Report on a red-tide research in Nakaumi. Bull Shimane Pref Fish Exp Sta 1932: 69-83. (in Japanese)

Shimane Prefecture (1958) Research on mass mortality of Mogai. Bull Shimane Pref Fish Exp Sta 1957-58: 273-280. (in Japanese)

Sobral P, Widdows J (1997) Influence of hypoxia and anoxia on the physiological responses of the clam Ruditapes decussatus from southern Portugal. Mar Biol 127: 455-461.

Suda K, Matsudaira Y, Takahata T, Mizu-uchi S (1929) Reports of the oceanographic observations on the Nakaumi. Kaiyojiho 3: 120-153. (in Japanese)

Sugino K, Yoshida M, Ito T, Matsui S (2009) Research on the mortality agents of Tairagi (Atrina pectinata) along Fukuoka region in Ariake Sea (II). Bulletin of Fukuoka Fisheries and Marine Technology Research Center 19: 83-90. (in Japanese)

Sukhotin AA, Pörtner HO (1999) Habitat as a factor involved in the physiological response to environmental anaerobiosis of White Sea Mytilus edulis. Mar Ecol Prog Ser 184: 149-160.

Suzuki H, Yamaguchi K, Seto K (2011) Growth and survival of the ark shell Scapharca kagoshimensis cltured in a semi-enclosed lagoon, Lake Nakaumi, southwest Japan. Aqua Sci 59: 89-99. (in Japanese with English abstract)

Uye S, Shimazu T, Yamamuro M, Ishitobi Y, Kamiya H (2000) Geographical and seasonal variations in mesozooplankton abundance and biomass in relation to environmental parameters in Lake Shinji-Ohashi River-Lake Nakaumi brackish-water system, Japan. J Mar Syst 26: 193-207.

Vaquer-Sunyer R, Duarte CM (2010) Sulfide exposure accelerates hypoxia-driven mortality. Limnol Oceanogr 55: 10751082.

Vistisen B, Vismann B (1997) Tolerance to low oxygen and sulfide in Amphiura filiformis and Ophiura albida (Echinodermata: Ophiuroidea). Mar Biol 128: 241-246.

Watanabe T, Shibata K, Kera Y, Takahashi S, Yamada R (2005) Effects of hypoxic and osmotic stress on the free D-aspartate level in the muscle of blood shell Scapharca broughtonii. Amino Acids 28: 291-296.

Yoshino K, Yamamoto K, Hayami Y, Hamada T, Kasagi T, Ueno D, Ohgushi K (2007) Benthic fauna of the inner part of Ariake Bay: long-term changes in several ecological parameters. Plankton Benthos Res 2: 198-212. 